\title{
A New AT14 Turbocharger with High Reliability and Durability*
}

Murano, ryuuma**

In recent years, technology for achieving higher compressor pressure ratio, higher performance and compactness has become an essential requirement in the design of turbochargers installed on 4 stroke diesel engines from the viewpoint of preventing global warming and air pollution and for achieving higher engine output and higher efficiency.

Under these circumstances, IHI has developed the radial type AT14 turbocharger with high reliability and durability. This new turbocharger was designed based on abundant experiences of IHI in field. AT14 turbocharger was subjected to run on the test-rig over a long period of time and confirmation tests with reliability and durability were conducted at various stages of development. The longest running hours of AT14 turbochargers reached almost 8,000 hours without any problem and the condition of the bearings are good for such long operating hours. These results show that AT14 turbocharger has enough reliability and durability even under the heavy fuel oil application.

\section{Introduction}

In recent years, technology for achieving higher compressor pressure ratio, higher performance and compactness has become an essential requirement in the design of turbochargers installed on 4 stroke diesel engines from the viewpoint of preventing global warming and air pollution and for achieving higher engine output and higher efficiency.

In addition to these technical requirements with turbocharger for the diesel engines, quality requirements such as longer maintenance interval, enhanced operability and life cycle cost reduction are also being strongly demanded. As a result marine diesel engines are operated with heavy fuel oil in most applications in recent years, turbocharger is being used under very severe conditions due to exhaust gas, lubrication oil pollution, etc. and users' demand for higher reliability and higher durability is becoming more severe year by year. In order to cope with these circumstances, manufacturers are working hard to improve their existing products and develop new products.

Under these circumstances, IHI has developed the radial type AT14 turbocharger with high reliability and durability. This new turbocharger was designed based on abundant experiences of IHI in field. Emphasis was laid on development of especially compressor, turbine and bearing in order to enhance reliability and durability. AT14 turbocharger was subjected to run on the test-rig over a long period of time and confirmation tests with reliability and durability were conducted at various stages of development.

* Received March 13, 2004

** Ishikawajima-Harima Heavy Industries Co., Ltd.
The longest running hours of AT14 turbochargers reached almost 8,000 hours without any problem and the condition of the bearings are good for such long operating hours. These results show that AT14 turbocharger has enough reliability and durability even under the heavy fuel oil application.

\section{Construction and outer dimensions of turbocharger}

A cross-sectional drawing and a cutting model of the AT14 turbocharger are shown in Fig.1, 2.

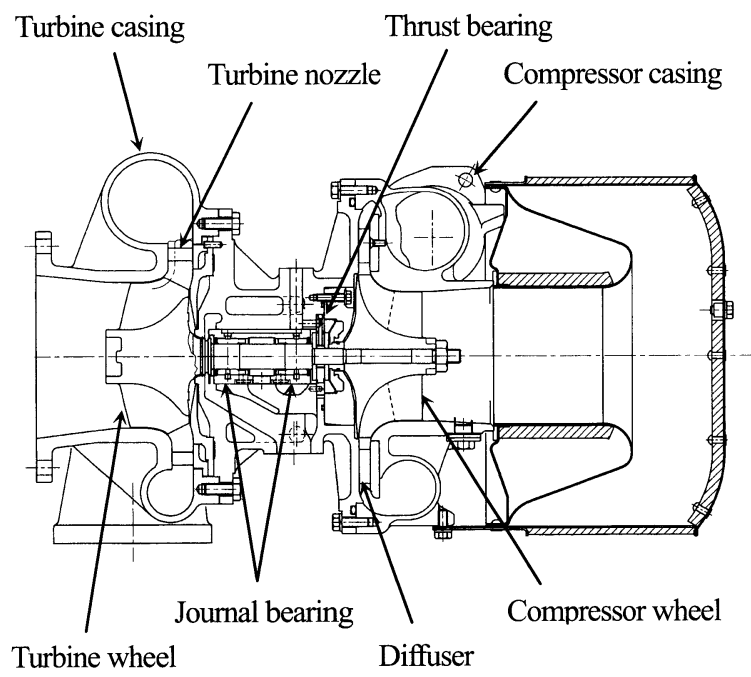

Fig.1 A cross-sectional drawing of the AT14 turbocharger

The rotating section consists of the turbine and compressor, and the thrust bearing and two journal bearings accept the axial and radial forces respectively. The static section consists of the turbine housing, bearing housing and 
compressor housing. Distance between two journal bearings is approximately $60 \mathrm{~mm}$ and the rotor length is approximately $300 \mathrm{~mm}$. Turbine inlet diameter and compressor outlet diameter, are approximately $\phi 140 \mathrm{~mm}$ each.

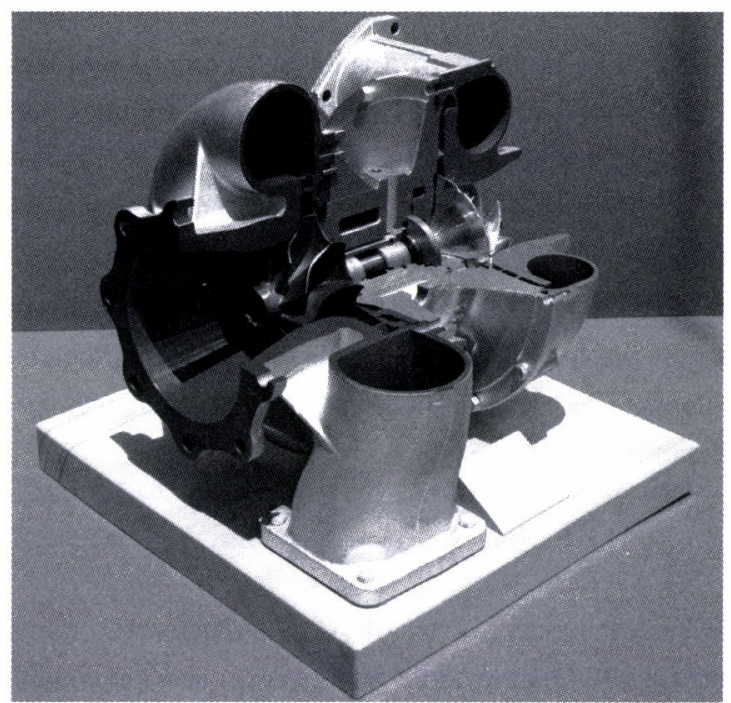

Fig.2 A cutting model of the AT14 turbocharger

\section{Development of elements}

\subsection{Compressor}

The new compressor was developed for AT14 turbocharger. It is a centrifugal compressor, backward-swept type made of forged aluminum with main blades and splitter ones, to achieve higher efficiency, larger volume flow rates and wide operating range. And vaned-diffuser is used to enhance peak efficiency and pressure ratio.

The maximum compressor pressure ratio reaches 4.2 under the very big air flow condition. The correlation between the volume flow rate ranges and pressure ratios is shown in Fig.3.

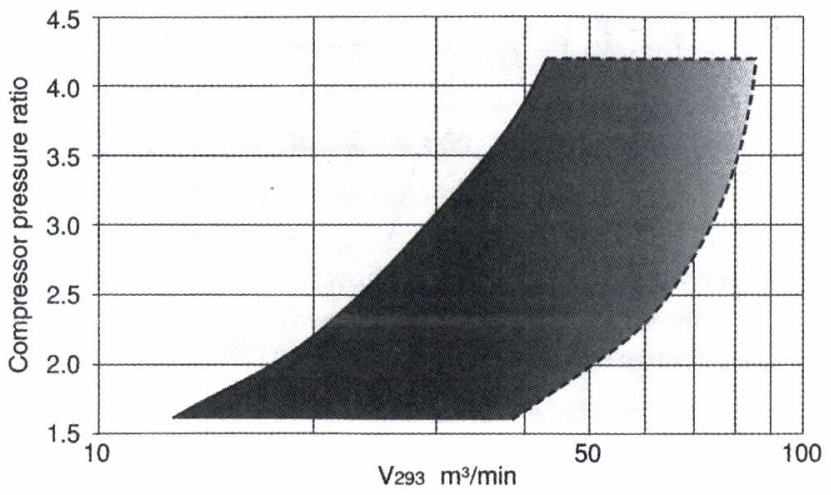

Fig. 3 The correlation between the volume flow rate ranges and pressure ratios

\subsection{Turbine}

Since turbine is used at high revolution and high temperature, Nickel-based heat resistant super alloy is adopted because of excellent characteristics for mechanical strength at high temperature and oxidation resistance. Two kinds of turbine, the radial flow and the mixed flow were developed by considering different exhaust gas flows, and inertia moment was lowered and in order to enhance the response of engine with regard to load change, a turbine of large capacity with as small in outer diameter as possible was developed. Moreover, by using turbine with turbine nozzle, IHI succeeded in enhancing efficiency with regard to design point.

\subsection{Bearing}

Based on the following design concept, the journal bearing and thrust bearing were developed.

\subsubsection{Journal Bearing}

A journal bearing is shown in Fig.4. Sliding bearing of semi-floating type was adopted for the journal bearing. The semi-floating type, journal bearing is fixed by the pins but it can be moved a little bit. The oil film is formed at both of inner and outer spaces and so the rotor movement is well damped by the squeezed oil film under the out of balance condition in rotor. As regards the construction of the bearing, the eccentricity ratio has been increased as compared to the perfect circular arcs by manufacturing the internal circumference into 3 circular arcs and accordingly bearing vibration has been suppressed.

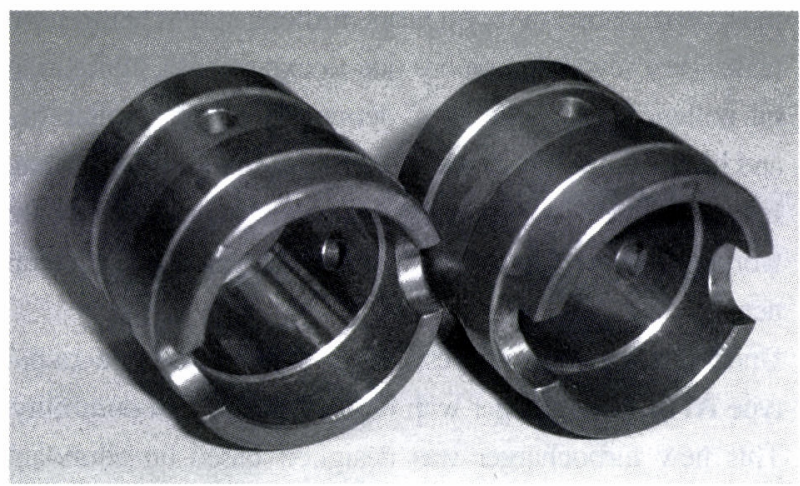

Fig.4 Journal bearing 
It explains concerning one of the analysis and measurement results about the design of the semi-floating type bearing. Damping coefficient factor, which decides bearing dynamic response, in case of short bearing width theory, is given by the equation (1).

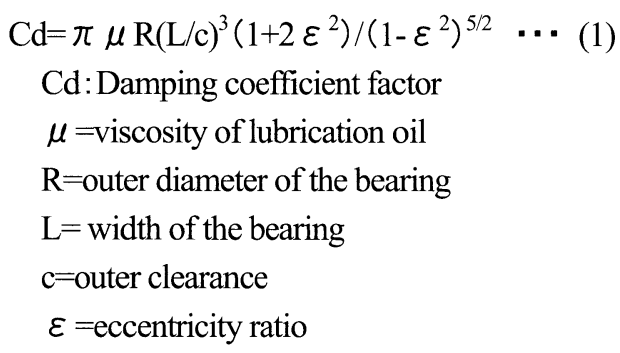

The damping coefficient factor performed optimization by the outer clearance and the width of the bearing.

IHI analysis the relationships of the rotational speed and the amplitude at the shaft end of compressor side changing damping coefficient factor, by the transfer matrix method. In addition, this is the analysis with excessive unbalance based on the investigation of the field than the design limit. The analysis results are shown in Figure 5.

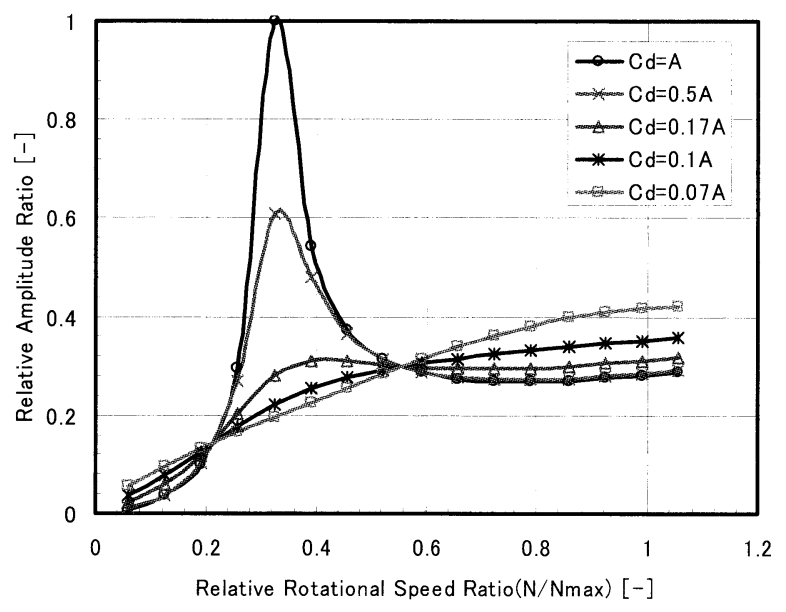

Fig.5 The analysis results

The bearing form is decided on the basis of these analysis results and temperature change of lubrication oil by operating condition. The measurement results of the amplitude at the shaft end on the test rig are shown in Figure 6. The unbalance quantity is the design limit and the excessive than the design limit.

The Figure 7 is the Campbell diagram at the above mentioned measurement when the unbalance quantity is the excessive than the design limit, it was confirmed that the $1 \mathrm{~N}$ rotor vibration is within allowable limit and the vibration about oil whip is nothing.

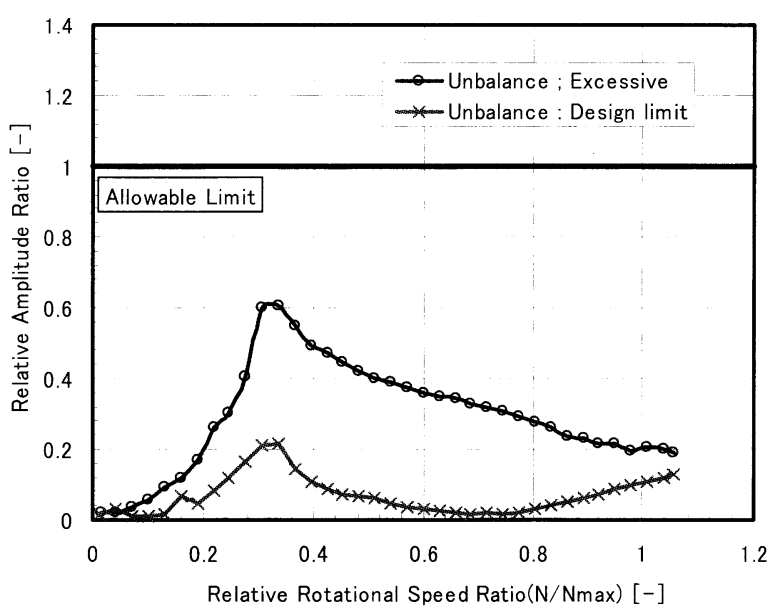

Fig.6 The measurement results

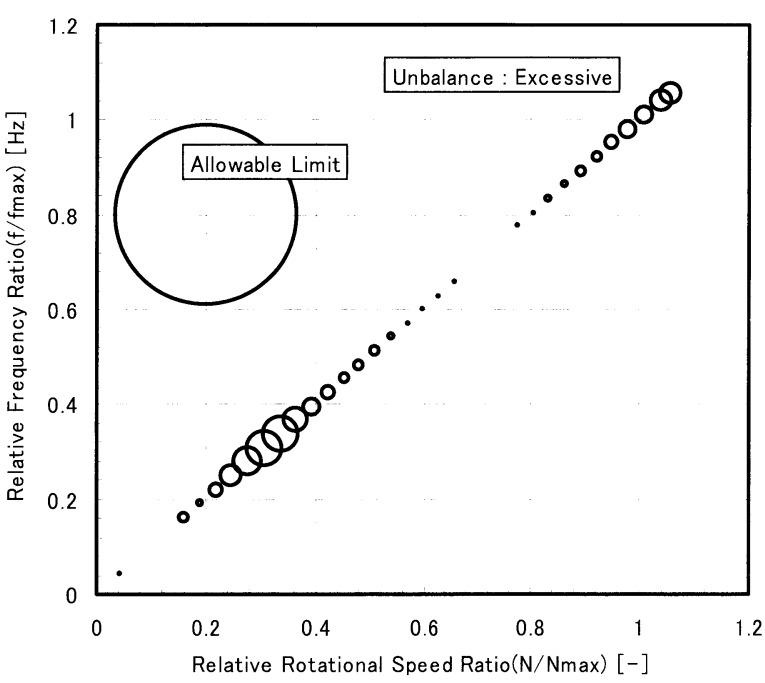

Fig.7 Campbell diagram 


\subsubsection{Thrust Bearing}

A thrust bearing is shown in Fig.8, 9. For the thrust bearing as well, sliding bearing of taper-land type was adopted. By such construction, IHI realized compact design superior in rotational stability up to high turbocharger speed range.

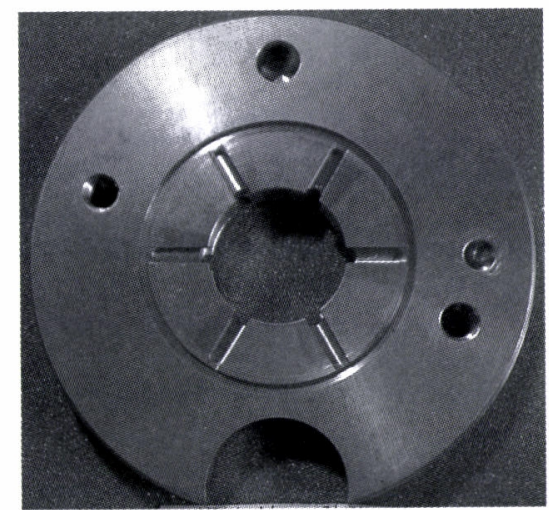

Fig.8 Thrust bearing (thrust side)

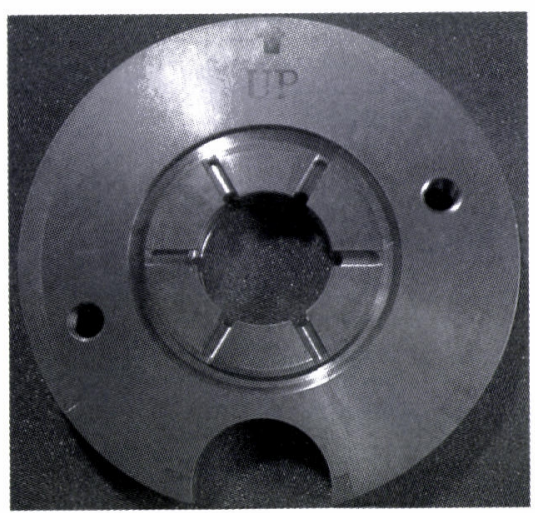

Fig.9 Thrust bearing (counter thrust side)

\section{Enhancement of reliability and durability}

\subsection{Heavy Fuel Oil Application}

Recently marine diesel engines are operated with heavy fuel oil in most applications and following malfunctions have been experienced in the conventional type of turbocharger due to the combustion residue in the exhaust gas.

-Damage caused by shroud touch due to the combustion residue on the turbine housing and shroud of turbine blades and due to insufficient maintenance of these parts. (Refer to the Fig.10)

-Damage caused by excessive rotor vibration due to unbalance arising from the combustion residue on the turbine blades.

-Erosion on the turbine housing flow path. (Refer to the Fig.11)
Following measures were taken in the development of AT14 turbocharger to prevent these malfunctions.

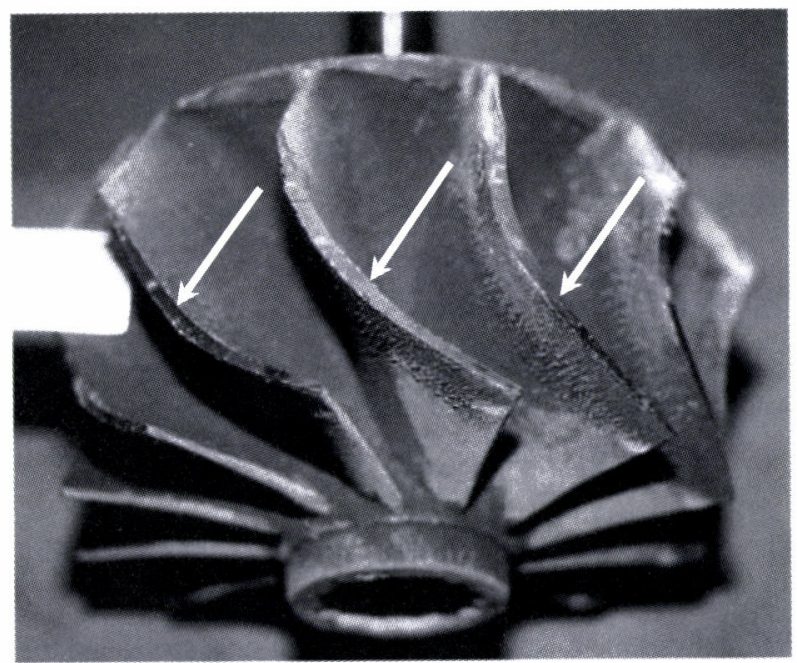

Fig.10 Damage caused by shroud touch with conventional type

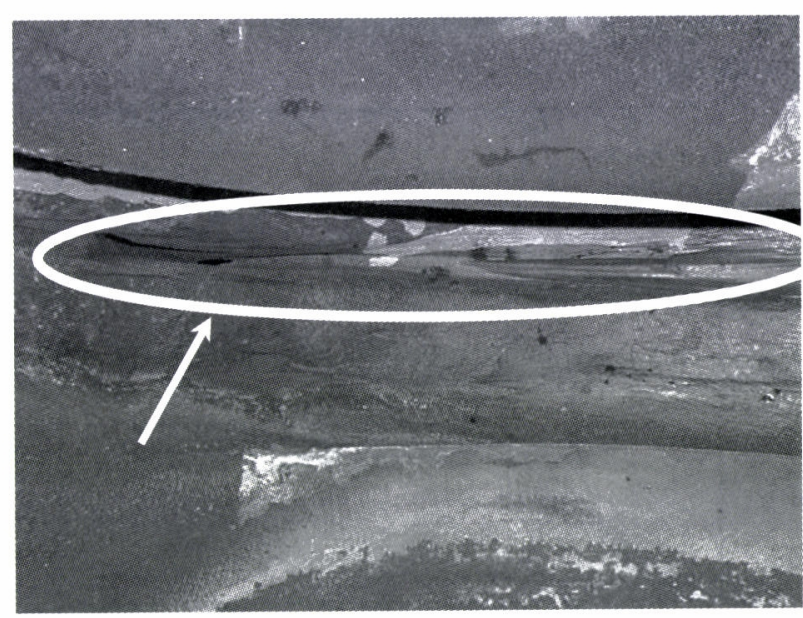

Fig.11 Erosion on the turbine housing flow path with conventional type 


\subsubsection{Turbine Cleaning with Water}

To avoid carbon deposit on the surface of turbine housing and tip of turbine blades during operation, turbine cleaning with water was introduced as standard. Turbine cleaning with water is a technique to clean the carbon deposit on the turbine housing and shroud of turbine blades by injecting water into the turbine part of the turbocharger during engine operation.

Turbine cleaning with water is adopted following device shown in Figure 12.

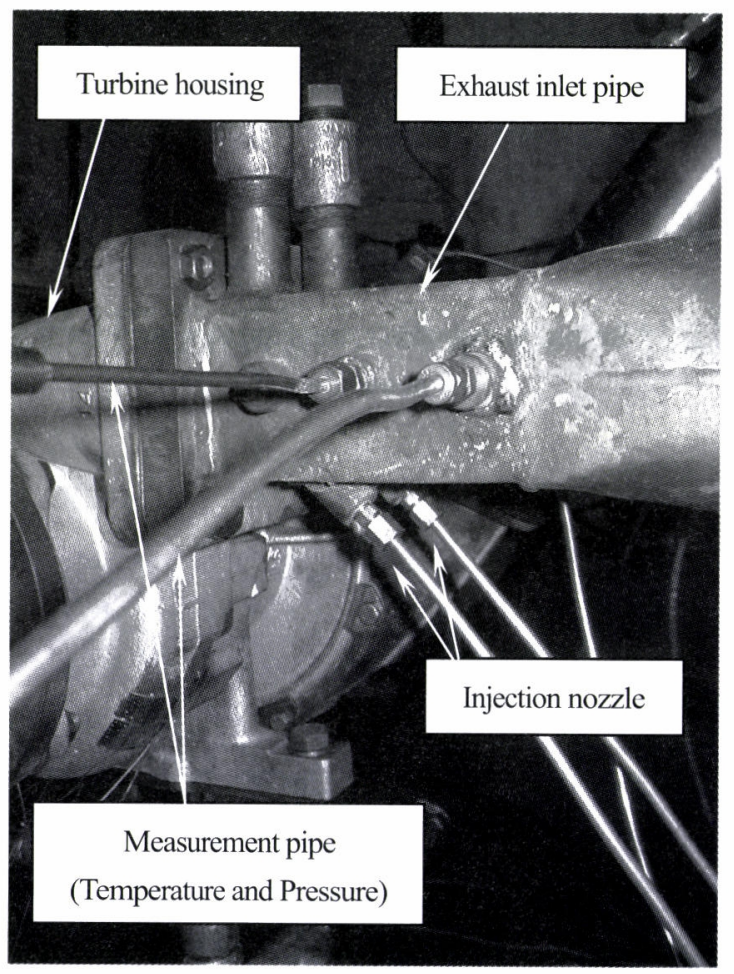

Fig.12 Turbine cleaning device without lagging jacket

The cleaning mechanism is following. Fresh water is injected into the exhaust pipe before turbocharger. The cleaning effect is based on the mechanical action of the impinging water droplets on the one hand, and on the water solubility of the carbon deposit on the other. IHI verified the effect of the turbine cleaning with water by running in field as monitor unit, from the fact that long operating time is necessary. From these results IHI confirmed turbine cleaning with water should be done before deposit not so heavy or just after the operating start. So the above mentioned mechanism, the water quantity and the exhasut gas temperature before turbocharger are determined not to evaporate the cleaning water.

The relationships of the operating time and the quantity of carbon deposit on the turbine rotor when the turbine cleaning with water has done and not is shown in Figure 13. From this figure, the effect which makes the carbon deposit decrease on the turbine rotor is confirmed by operating turbine cleaning with water.

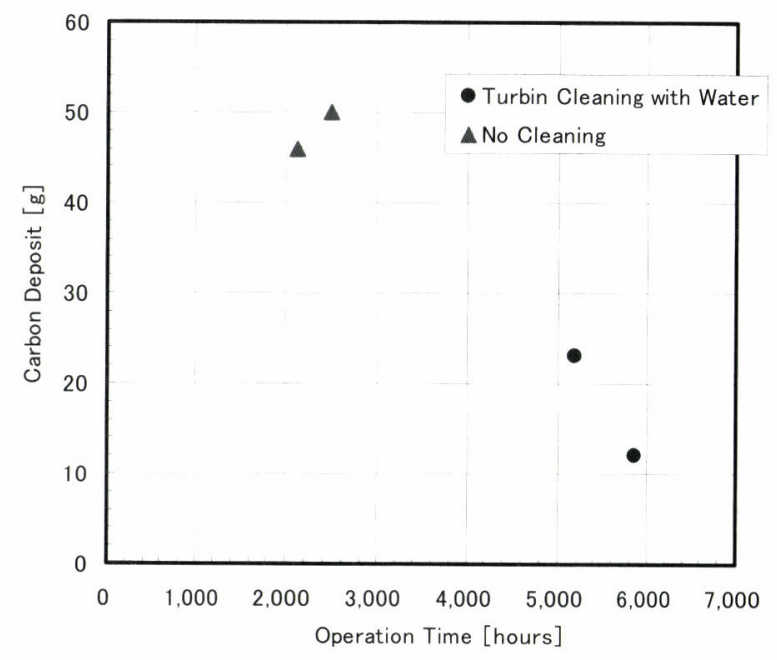

Fig.13 The quantity of carbon deposit by operating time

By standardizing turbine cleaning with water, the amount of carbon deposit on the turbine housing and shroud of turbine blades can be considerably reduced, as a result the damage caused by shroud touch and excessive rotor vibration could be prevented. This shows that this turbine cleaning by water enhances the reliability under the operation by heavy fuel oil. The appearance of the turbine wheel before and after the cleaning with water is shown in Fig. 14.
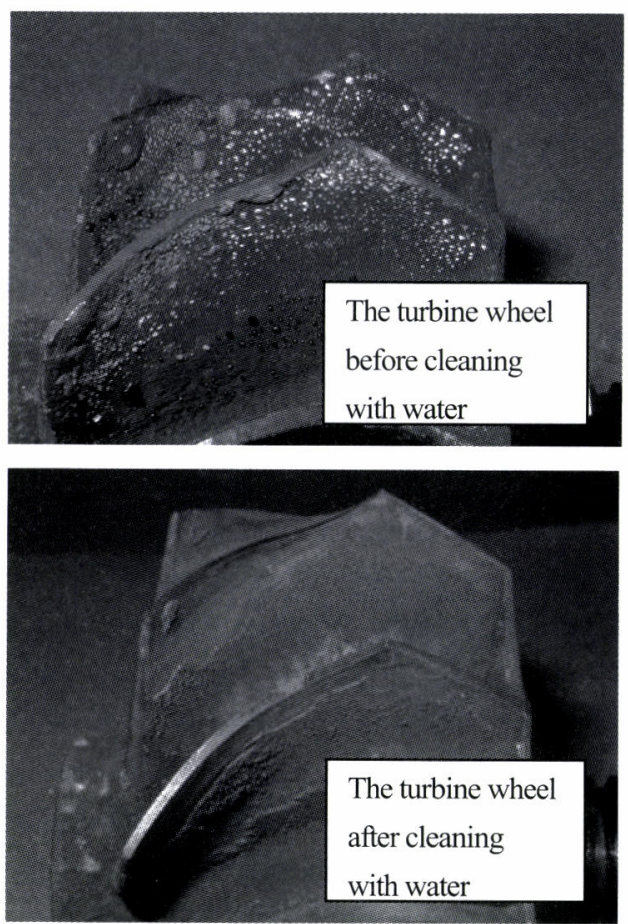

Fig.14 The appearance of the turbine wheel with conventional type before and after the cleaning with water 
4.1.2 Journal Bearing of Semi-Floating Type

The amount of the combustion residue on the turbine blades by standardization of the turbine cleaning with water cannot be nothing though is decreased greatly. Then the journal bearing of semi-floating type was applied to decrease an excessive rotor vibration due to unbalance arising from the combustion residue on the turbine blades. This semi-floating bearing has the feature of suppressing unstable vibration such as self-excited vibration or forced vibration produced by unbalance caused by deposited carbon, etc. as compared to the full-floating type bearing used until now.

\subsubsection{Coated Turbine Housing for Erosion}

Conventional type had experienced erosion problem on the turbine housing due to the effect of combustion residue in the exhaust gas of engines using heavy fuel oil, but later on considerable increase in life time was achieved by the special coating on the said flow part.

As for the AT14 turbocharger that can be used on engines using heavy fuel oil as well in view of that experience mentioned above, the erosion on the turbine housing flow path was avoided by the design adopting the turbine with the turbine nozzle. Therefore turbine nozzle can be coated as an option though no erosion problem is expected on the turbine housing.

By taking above-mentioned measures, erosion caused by the combustion residue contained in the exhaust gas of engines using heavy fuel oil has been prevented.

\subsection{Turbine Blade}

Generally matching of the blade's characteristic vibrations with the harmonic vibration component of the revolutions produces the resonance vibration of turbine blade. Since the turbochargers rotate at very high revolutions, resonance vibration up to higher order mode of revolutions cannot be avoided. Therefore, in case of AT14 turbocharger IHI measured resonance vibration stress in each mode up to the highest revolution and confirmed about the safety.

In actual engines the compressor intakes air from the silencer normally, resonance vibration stress measurement results of turbocharger alone are simulated on test-rig, but as regards the turbine blades, because of the pulsation effect of exhaust gas, it is difficult to evaluate by results of measurement of turbocharger alone on test-rig. For this reason, in case of AT14 turbocharger IHI not only conducted measurement of turbocharger alone on test-rig, but also conducted vibration stress measurement on actual engine and confirmed that it is safe stress level at which resonance damage does not occur even under the strong pulsation of exhaust gas. Resonance vibration stress measurement results on test-rig and on actual engine show in Fig.15, 16. The circle diameter shows the vibration stress. The whole measured stress was very small and confirmed that it is reliable value.

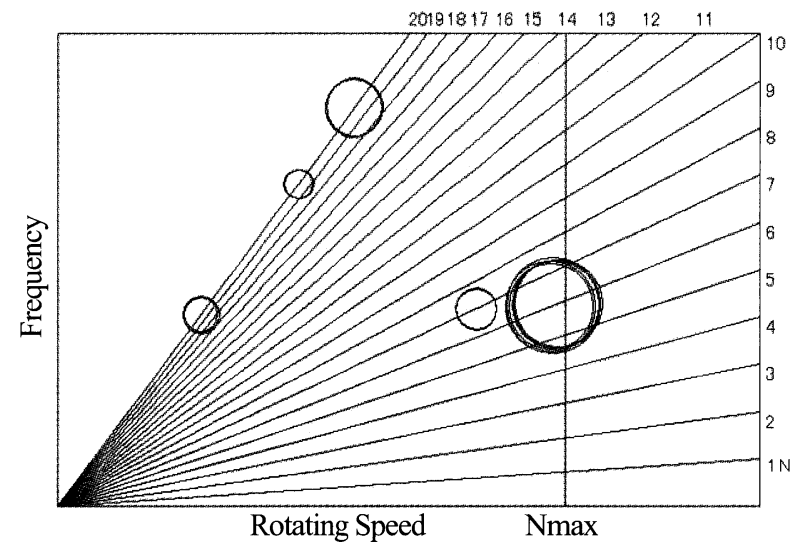

Fig.15 Resonance vibration stress measurement results on test-rig

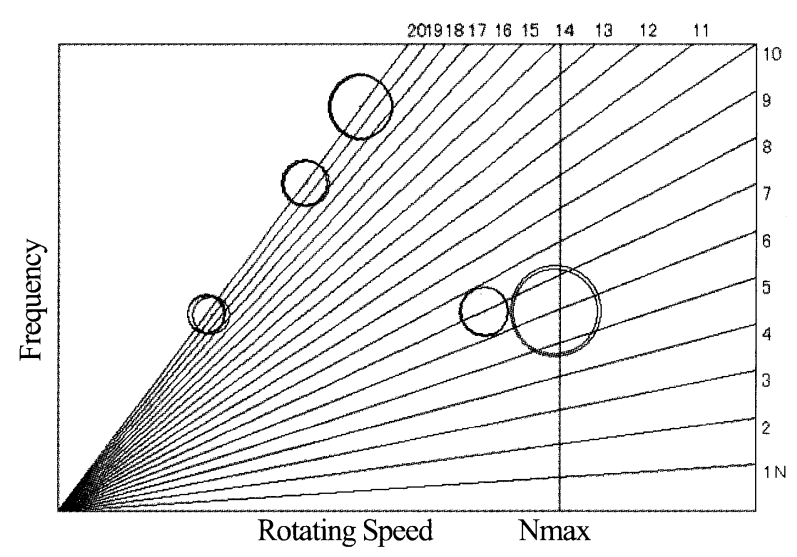

Fig.16 Resonance vibration stress measurement results on actual engine

\subsection{Field Test}

The first AT14 turbocharger is running in field since January 2003 and about 400 turbochargers are running successfully so far without any problems. After about 8,000 hours of operation in field as monitor unit, the turbochargers were disassembled to check about turbocharger condition. Photographs of the various parts are shown below. This monitor unit has overhauled one time and ran about 8,000 hours. No abnormality was found in the turbine shaft, turbine wheel, bearing parts etc. and the parts were confirmed to be operating normally. As a result, even after about 8,000 hours of actual operation, no abnormal abrasion, erosion, and cracks, etc. were found and the parts were confirmed to be operating normally. 


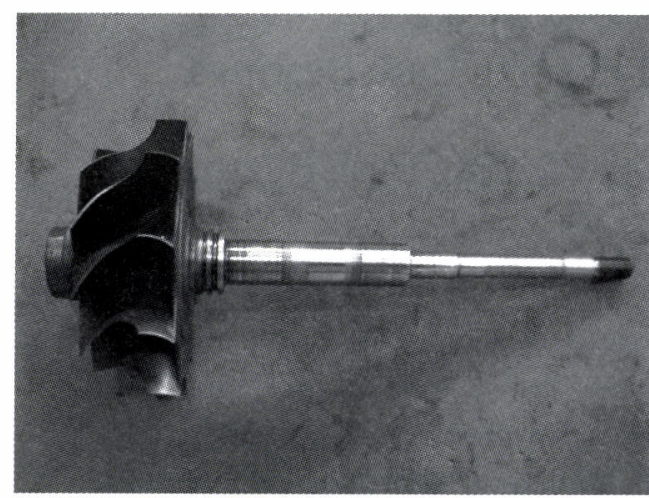

Fig.17 Turbine shaft

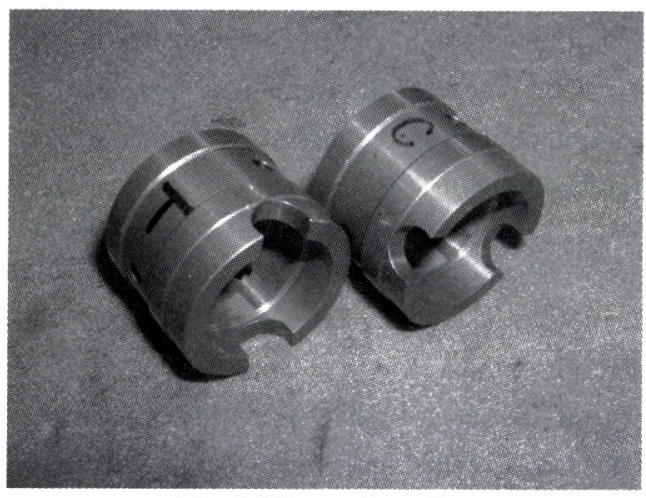

Fig. 18 Journal bearing

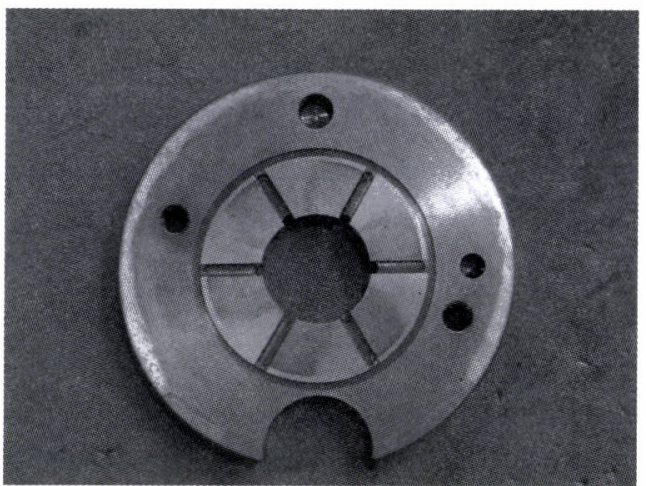

Fig. 19 Thrust bearing (thrust side)

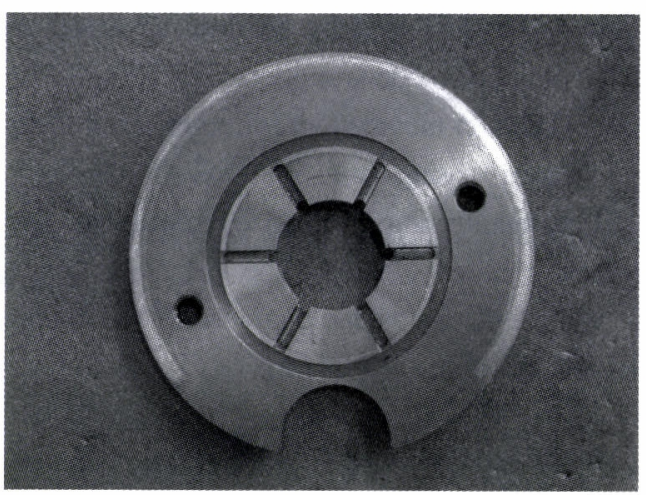

Fig. 20 Thrust bearing (counter thrust side)

\section{Conclusion}

Through development of various elements as described above and through various measures IHI succeeded in developing radial type AT14 turbocharger and more than 8,000 hours of actual run on field engines proved its reliability and durability. To achieve further improvements in the AT14 turbocharger, continuous efforts will be made to further improve performance, prolong maintenance interval and enhance reliability and durability. In future also IHI intends to develop and put on market high performance and high reliability turbochargers matching with the market needs to enhance awareness regarding recent environmental problems and cope with exhaust gas regulations, etc.

\section{References}

[1] Sekita, Y., "Journal of the Gas Turbine Society of Japan" Vol.31, No.1 (2003), p26.

[2] Sekita, Y., "Turbomachinery" Vol.32, No.7 (2004), p413

[3] Iwaki, F., Mitsubori, K., "IHI ENGINEERING REVIEW" Vol.37, No.1 (2004), p35.

[4] Koike, T., Iwaki, F., "Journal of the Gas Turbine Society of Japan” Vol.33, No.2 (2005), p80.

[5] Mori, H., Hirata, U., "Journal of the Gas Turbine Society of Japan” Vol.33, No.4 (2005), p262.

Authors

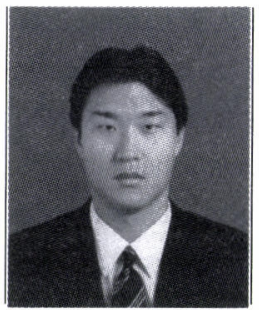

- Murano, ryuuma

· Born in 1973

- Ishikawajima-Harima Heavy

Industries Co., Ltd. 